\title{
Potensi Pemanfaatan Tanaman Thypa sp dan Cyperus sp dalam Proses Remediasi Air Asam Tambang dengan Sistem Rawa Buatan
}

\section{Apong Sandrawati1, Darmawan², Dyah Tj. Suryaningtyas ${ }^{2}$, dan Gunawan Djadjakirana²}

\author{
1) Staf Pengajar Fakultas Pertanian Universitas Padjadjaran \\ Jl. Raya Bandung Sumedang Km 21 Jatinangor \\ 2) Staf Pengajar Departemen Managemen Sumberdaya Lahan, Institut Pertanian Bogor \\ Jl. Meranti, Kampus IPB Dramaga Bogor \\ Korespondensi: apong.sandrawati@unpad.ac.id
}

\begin{abstract}
Acid mine drainage (AMD) is the main problem in open pit mining due to extremely low $p H$ and high solubility of metals. Metal solubility can be reduced biochemically in an anaerobic condition. This research was aimed to design and test artificial wetland system constructed. The artificial wetland has been constructed, it contains with two organic wall, two growing pond, and one collecting pond, each component bounded by dike. Organic wall was placed next to growing pond that planted by Typha sp and Cyperus sp. Collecting pond was planted by Eichornia crassipes. Iron and Manganese were accumulated in the root of each plant. Cyperus sp has a fibril type while Typha sp has rhizome type. The fine roots such as root of Cyperus sp could accumulation Fe higher than a rhizome roots such as root of Typha sp. Productivity of biomass was 31,38 ton/ha for Eichornia crassipes, 17,11 ton/ha for Typha sp, and 16,67 ton/ha for Cyperus sp. Eichornia crassipes has a higher biomass than other plants, but the size of this plant become smaller, it because the lack of nutrient in collecting ponds. Cyperus sp seems more prospective, this plant has better of growth rate than other plants.
\end{abstract}

Keywords: artificial wetland, Cyperus sp., Typha sp., root accumulation, type of root, plant productivity

\section{PENDAHULUAN}

Air asam tambang (AAT) merupakan salah satu permasalahan utama di lokasi pertambangan batubara yang dilakukan dengan penambangan terbuka. Pembentukkan AAT terjadi akibat adanya bahan timbunan bekas tambang (overburden) yang mengandung mineral sulfida, seperti Pirit $\left(\mathrm{FeS}_{2}\right)$ yang tersing-kap dan bereaksi dengan oksigen di udara maupun dalam air (Holmstrom, 2000 dalam Nyquist dan Greger, 2009). Karakteristik AAT tidak dapat dipisahkan dari nilai $\mathrm{pH}$ yang sangat rendah dan kelarutan logam yang tinggi, yang dinilai berbahaya bagi kehidupan flora dan fauna.

Upaya pengelolaan AAT dapat dilakukan dengan teknik perlakuan aktif (active treatment) dan perlakuan pasif (passive treatment). Perlakuan aktif antara lain dengan menam-bahkan bahan-bahan alkalin, seperti kapur $\left(\mathrm{CaCO}_{3}\right)$, sedangkan perlakuan pasif pada prinsipnya membiarkan reaksi kimia dan biologi berlangsung secara alami (Skousen dan Ziemkiewicz, 1996). Salah satu passive treatment adalah rawa buatan.

Rawa buatan merupakan salah satu teknik yang telah banyak diaplikasikan dalam upaya memperbaiki kualitas air. Rawa buatan terdiri atas air, bahan padatan (tanah atau lumpur) dan tanaman (Davis, 1995). Tanaman merupakan salah satu komponen rawa buatan yang harus diperhitungkan sebagai penghasil biomassa yang dapat digunakan untuk kepentingan lain. Informasi mengenai kualitas dan produktivitas tanaman sangat penting sebagai pertimbangan kelayakan penggunaan biomassa tanaman tersebut untuk kepentingan tertentu.

Penelitian ini bertujuan untuk mengidentifikasi peran tanaman dalam proses perbaikan kualitas air asam tabang dalam sebuah sistem rawa buatan. Identifikasi juga 
dilakukan terhadap produksi biomassa yang dapat dihasilkan dari rawa buatan.

\section{BAHAN DAN METODE}

\subsection{Rancangan Rawa Buatan}

Rancangan rawa buatan terdiri dari 2 (dua) organic wal (OW), 2 (dua) kolam pertumbuhan, dan kolam penampungan
(Gambar 1). Kolam pertumbuhan pertama (KP 1) ditanami dengan Typha sp (Gambar 2a), Kolam pertumbuhan kedua (KP 2) ditanami dengan Cyperus sp (Gambar 2b), sedangkan kolam penampungan (KP 3) ditanami dengan Eichornia crassipes (Gambar 2c). Bahan pengisi kolam pertumbuhan terdiri atas: lumpur endapan settling pond dan bahan organik kering.

$$
\begin{array}{ccccc}
\text { Organic } & \text { Kolam } & \text { Organic Wall } & \text { Kolam } & \text { Kolam } \\
\text { Wall satu } & \text { Pertumbuhan satu } & \text { dua } & \text { Pertumbuhan dua } & \text { Pertumbuhan } \\
& & & \text { tiga }
\end{array}
$$

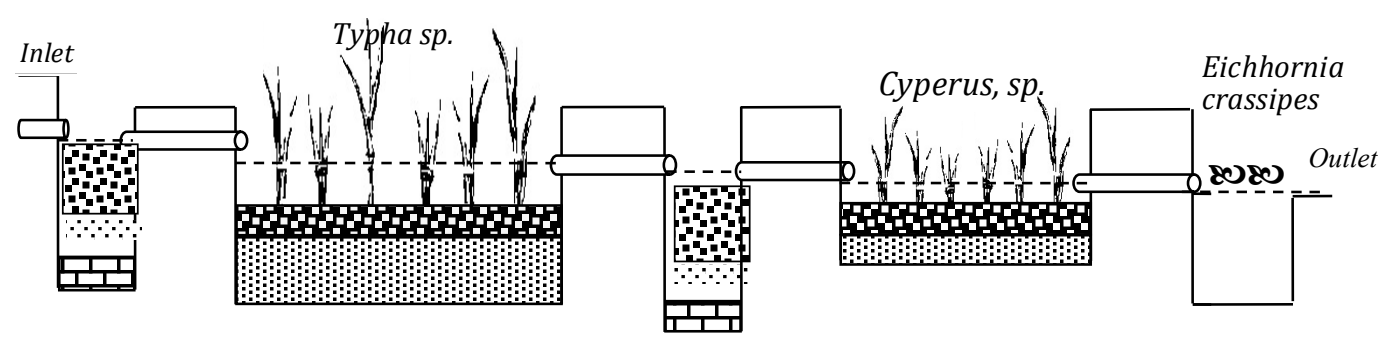

Keterangan :

\begin{tabular}{llll}
$\square$ & Pipa & Batu kapur $\left(\mathrm{CaCO}_{3}\right)$ \\
\hdashline-19 & Permukaan air & Bahan organik segar & Bahan organik kering \\
$\because$ & Lumpur endapan AAT & Lumpur endapan settling pond
\end{tabular}

\section{Gambar 1 Rancangan rawa buatan}

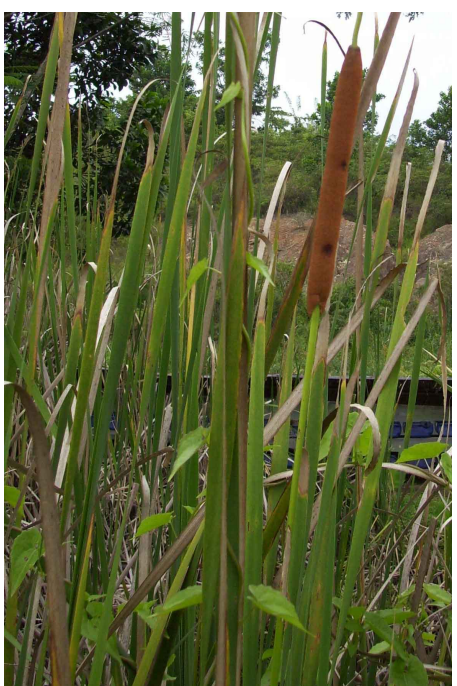

a

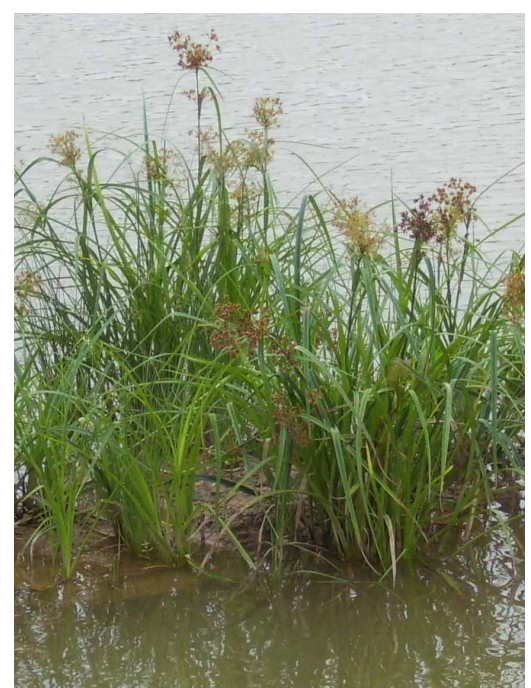

b

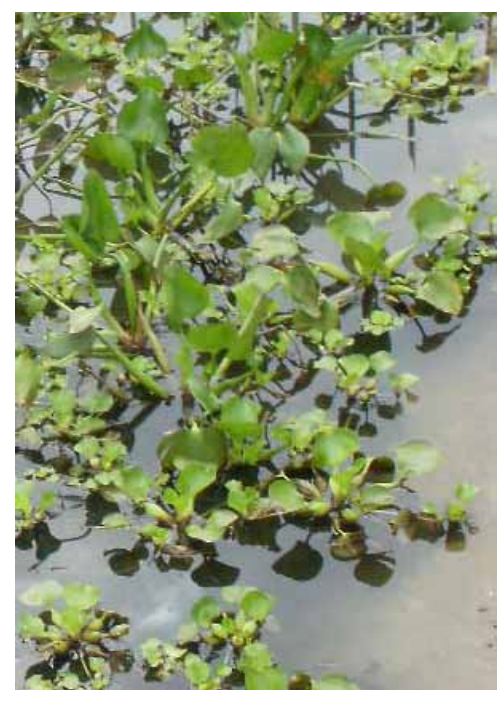

C

Gambar 2 Tanaman komponen rawa buatan; Typha sp (a) nama lokal ekor kucing; Cyperus sp (b) nama lokal teki-tekian; dan Eichornia crassipes (c) nama lokal eceng gondok 


\subsection{Penanaman}

Penanaman dilakukan setelah inkubasi tahap pertama. Sebelum penanaman, air dari kolam pertumbuhan dibuang sampai kondisinya macak-macak, sehingga penanaman dapat lebih mudah. Typha sp ditanam dengan jarak tanam $75 \mathrm{~cm} \times 75 \mathrm{~cm}$, Cyperus sp $30 \mathrm{~cm} \times 30 \mathrm{~cm}$, dan eceng gondok (Eichornia crassipes) disebar langsung di atas kolam.

\subsection{Pengoperasian Rawa Buatan}

Pengoperasian dilakukan dengan mengalirkan AAT melalui titik inlet. Debit air yang masuk diatur melalui pintu di titik tersebut. Secara berturut turut air akan mengalir melalui: inlet- OW1-KP1-OW2-KP2KP3-outlet.

\subsection{Pengambilan dan Pengukuran Contoh}

Pengambilan contoh tanaman dilakukan setelah tahap pengoperasian dengan umur tanaman 4 minggu setelah tanam (dihitung dari masa inkubasi dan pengoperasian). Penghitungan produktivitas dilakukan secara ubinan. Ukuran plot ubinan $1,5 \mathrm{~m} \mathrm{x} 1,5 \mathrm{~m}$ untuk tanaman Typha $s p$ dan $0,6 \mathrm{~m} \times 0,6 \mathrm{~m}$ untuk Cyperus sp. Analisis laboratorium dilakukan pada setiap contoh yang diambil, metoda pengukuran contoh diuraikan dalam Tabel 1.

Tabel 1 Metode pengukuran contoh tanaman

\begin{tabular}{cl}
\hline $\begin{array}{c}\text { Parameter } \\
\text { Analisis }\end{array}$ & \multicolumn{1}{c}{ Metode Pengukuran } \\
\hline Produktivitas & $\begin{array}{l}\text { Berat biomassa ubinan } \\
\text { Total Sulfur }\end{array}$ \\
$\begin{array}{l}\text { basah } \\
\text { Fe dan Mn }\end{array}$ & $\begin{array}{l}\text { Spektrofotometri, } \\
\text { pengabuan kering }\end{array}$ \\
\hline
\end{tabular}

\subsection{Analisis dan Penyajian Data}

Data hasil pengukuran baik yang dilakukan di lapang maupun di laboratorium dipetakan ke dalam grafik untuk melihat trend data dari titik inlet sampai outlet pada setiap pengukuran.

\section{HASIL DAN PEMBAHASAN}

\subsection{Proses Perbaikan Kualitas AAT}

Pengoperasian rawa buatan secara kontinyu dilakukan setelah tahap inkubasi selesai, dimana rawa sudah dalam kondisi yang reduktif. Berdasarkan hasil pemantauan data kualitas air (Tabel 2), air pada titik outlet telah berada pada ambang batas baku sesuai dengan ketetapan pada Keputusan Menteri Negara Lingkungan Hidup Nomor 113 Tahun 2003.

Tabel 2 Hasil pengamatan kualitas air $(\mathrm{pH}$, kadar Fe dan Mn) air selama pengoperasian rawa buatan

\begin{tabular}{ccccccc}
\hline \multirow{2}{*}{$\begin{array}{c}\text { Hari } \\
\text { Ke- }\end{array}$} & \multicolumn{2}{c}{$\mathrm{pH}$} & \multicolumn{2}{c}{$\mathrm{Fe}(\mathrm{mg} / \mathrm{l})$} & \multicolumn{2}{c}{$\mathrm{Mn}(\mathrm{mg} / \mathrm{l})$} \\
\cline { 2 - 7 } & Inlet & outlet & inlet & outlet & inlet & Outlet \\
\hline 0 & 3,02 & 4,59 & 7,86 & 1,29 & 3,86 & 4,18 \\
2 & 3,22 & 5,76 & 5,62 & 0,93 & 4,11 & 2,68 \\
4 & 3,12 & 6,34 & 5,78 & 0,54 & 4,02 & 1,43 \\
6 & 3,08 & 6,58 & 6,16 & 0,87 & 3,68 & 0,01 \\
8 & 3,06 & 6,71 & 6,45 & 1,30 & 3,58 & 0,01 \\
10 & 3,05 & 6,67 & 7,40 & 0,21 & 4,56 & 0,69 \\
12 & 3,12 & 6,36 & 12,35 & 0,01 & 5,63 & 1,57 \\
14 & 2,84 & 6,28 & 6,72 & 0,01 & 3,83 & 0,01 \\
16 & 3,08 & 6,35 & 5,95 & 0,01 & 4,73 & 0,00 \\
\hline
\end{tabular}

\subsection{Kadar Besi dan Mangan pada Tanaman}

Tanaman merupakan komponen penting dalam proses remediasi di lingkungan lahan basah. Salah satu peran tanaman adalah sebagai penyedia tapak untuk menempelnya mikroba, mengeluarkan oksigen dari akarnya, dan menyediakan sumber bahan organik untuk mikroba heterotrof (Skousen et al., 1998). Oleh karena itu, proses reduksi dan oksidasi besi dan mangan akan lebih banyak 
terjadi pada daerah perakaran karena kelimpahan mikroorganisme (termasuk bakteri pereduksi) yang tinggi.

Jenis tanaman air mempengaruhi proses penyerapan bahan-bahan pencemar (Zayed et al., 1998 dalam Yang dan Ye, 2009). Tabel 3 menunjukkan konsentrasi total $\mathrm{Fe}$ dan $\mathrm{Mn}$ pada tanaman yang diukur pada bagian akar dan daun sebelum dan sesudah perlakuan.

Tabel 3 Konsentrasi total besi dan mangan pada akar dan daun tanaman contoh

\begin{tabular}{lcccc}
\hline \multirow{2}{*}{$\begin{array}{l}\text { Contoh } \\
\text { Tanaman }\end{array}$} & \multicolumn{2}{c}{ Fe (\%) } & \multicolumn{2}{c}{ Mn (\%) } \\
\cline { 2 - 5 } & Akar & Daun & Akar & Daun \\
\cline { 3 - 5 } Typhasp & & & & \\
- Sebelum & 1,20 & 0,19 & 0,02 & 0,02 \\
- Sesudah & 1,41 & 0,21 & 0,04 & 0,03 \\
Cyperus sp & & & & \\
- Sebelum & 2,41 & 0,57 & 0,02 & 0,01 \\
- Sesudah & 2,01 & 0,67 & 0,03 & 0,02 \\
Eichornia Crassipes & & & \\
- Sebelum & 1,91 & 0,53 & 0,24 & 0,03 \\
- Sesudah & 1,91 & 0,34 & 0,17 & 0,01 \\
\hline
\end{tabular}

Berdasarkan hasil pengukuran (Tabel 3), kadar Fe dan Mn lebih tinggi pada bagian akar tanaman dibandingkan dengan bagian daun. Akar tanaman bertindak sebagai permukaan jerapan bagi besi dan mangan. Besi dan mangan terakumulasi pada bagian permukaan akar, sehingga konsentrasi unsur-unsur tersebut lebih tinggi daripada daun (Surface et al. 1993, dalam Munawar 2007).

Nadar Fe pada akar tanaman Cyperus sp. lebih tinggi jika dibandingkan dengann akar tanaman Typha sp. Hal ini dapat disebabkan oleh pengaruh tipe akar yang berbeda. Cyperus sp. mempunyai tipe akar serabut (Gambar 3a) sedangkan Typha sp. mempunyai tipe akar rimpang (Gambar 3b). Menurut Chen et al. (2007) tipe akar serabut dengan ukuran akar yang halus akan mengakumulasikan unsur hara lebih banyak dibandingkan dengan tanaman yang mempunyai tipe akar rhizome atau rimpang.

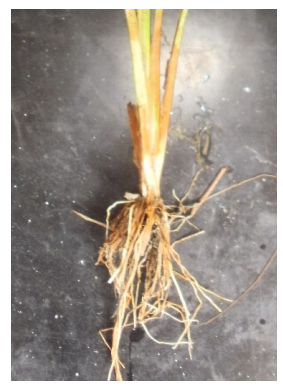

a

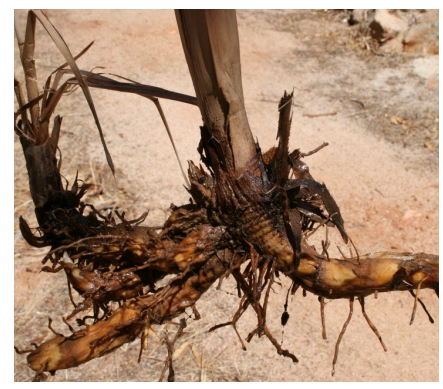

b
Gambar 3 Tipe akar Cyperus sp.(a); tipe akar Typha (b).

Penentuan terjadinya akumulasi Fe dan Mn dalam jaringan tanaman dilakukan melalui pembandingan konsentrasi besi dan mangan terukur dengan konsentrasi normal unsur-unsur tersebut dalam tanaman. Bohn et al. (1979) menghitung konsentrasi unsurunsur hara esensial dalam berat basah tanaman. Tabel 4 mengkonversi nilai konsentrasi tersebut menjadi persentase dalam berat kering.

Tabel 4 Konsentrasi normal dari unsur hara esensial pada tanaman (Bohn et al., 1979)

\begin{tabular}{|c|c|c|c|}
\hline \multirow[b]{2}{*}{ Unsur } & \multicolumn{3}{|c|}{$\%$ Berat kering } \\
\hline & Typha sp. & Cyperus sp. & $\begin{array}{l}\text { Eichornia } \\
\text { Crassipes }\end{array}$ \\
\hline $\mathrm{Fe}$ & 0,017 & 0,017 & 0,020 \\
\hline $\mathrm{Mn}$ & 0,002 & 0,002 & 0,002 \\
\hline
\end{tabular}

Hasil pembandingan antara konsentrasi besi dan mangan pada tanaman contoh terhadap nilai konsentrasi normal tanaman, menunjukkan bahwa kandungan unsur-unsur tersebut melebihi kandungan normalnya. Tanaman tidak saja mengakumulasi $\mathrm{Fe}$ dan Mn pada permukaan akar, tapi juga mengakumulasikannya pada jaringan tanaman bagian atas (daun dan batang). Hal ini berlaku pada semua tanaman contoh. 


\subsection{Produktivitas Tanaman}

Tingginya konsentrasi Fe dan Mn pada jaringan tanaman dipengaruhi oleh tingginya unsur-unsur tersebut dalam AAT yang menjadi air genangannya. Tingginya kadar Fe dan $\mathrm{Mn}$ menjadi pertimbangan dalam penilaian produktivitas tanaman tersebut.

Besi berperan dalam proses dasar biologi tanaman seperti fotosintesis, pembentukkan klorofil, dan respirasi (Keem dan Rees, 1992 dalam Rout and Sahoo, 2015). Namun, akumulasi Fe yang tinggi dapat menyebabkan defisiensi unsur hara yang lain seperti Mn, P, K, Ca, dan Mg (Howeler, 1973, Ottow et. al., 1982 dalam Rout and Sahoo, 2015).

Produktivitas tanaman dinilai dari berat biomassa dan jumlah anakan tanaman. Berat biomassa (basah) dihitung berdasarkan hasil panen ubinan yang dikonversi ke dalam satuan hektar. Hasil pengukuran produktivitas tanaman dapat dilihat pada Tabel 5.

Tabel 5 Produktivitas tanaman (angka ratarata dari hasil ubinan)

\begin{tabular}{lccc}
\hline $\begin{array}{c}\text { Jenis } \\
\text { Tanaman }\end{array}$ & $\begin{array}{c}\text { Jumlah } \\
\text { Anakan }\end{array}$ & $\begin{array}{c}\text { Berat } \\
\text { Biomassa } \\
\text { (kg) }\end{array}$ & $\begin{array}{c}\text { Produktivitas } \\
\text { (ton/ha) }\end{array}$ \\
\hline Typha sp & 6 & 3,84 & 17,11 \\
$\begin{array}{l}\text { Cyperus sp } \\
\text { Eichhornia }\end{array}$ & 2 & 0,58 & 16,67 \\
crassipes & 7 & 3,14 & 31,38 \\
\hline
\end{tabular}

Secara kuantitatif tanaman Eichhornia crassipes mempunyai produktivitas tertinggi (31,38 ton/ha), namun ukuran tanaman ini makin lama makin kecil. Hal ini diduga karena eceng gondok kekurangan nutrisi, mengingat di kolam terakhir kelarutan unsur-unsur terutama $\mathrm{Fe}, \mathrm{Mn}$, dan $\mathrm{SO}_{4}$ sangat kecil.

Biomassa yang di hasilkan oleh tanaman Typha sp memang lebih kecil daripada Eichhornia crassipes, namun, tanaman ini memperlihatkan kondisi yang lebih baik selama pertumbuhannya. Tanaman Cyperus sp dapat menghasilkan biomassa dengan jumlah yang tidak jauh berbeda dengan tanaman Typha sp. Pertimbangan pemakaian kedua tanaman ini harus memperhatikan syarat tumbuhnya, dimana Cyperus sp tidak tahan dengan genangan air yang tinggi sedangkan Typha sp lebih tahan terhadap genangan air yang tinggi. Dengan demikian untuk memperoleh biomassa yang tinggi dan kualitas tanaman yang baik, maka tanaman Typha sp lebih dianjurkan ditanam pada rawa buatan dibandingkan tanaman lainnya.

\section{KESIMPULAN}

Kadar Fe dan Mn dalam akar lebih tinggi dari daun. Akumulasi Fe pada akar tanaman Cyperus sp dengan tipe serabut lebih tinggi dari tanaman Typha sp. yang mempunyai tipe akar rizome atau rimpang. Berdasarkan produktifitasnya, tanaman Typha sp dapat direkomendasikan sebagai tanaman rawa yang mempunyai produktivitas tinggi. Namun, Cyperus sp. mempunyai kemampuan mengakumulasikan Fe lebih tinggi.

Potensi pemanfaatan hasil biomassa yang dihasilkan sebagai sumber bahan organik, di mana biomassa tanaman tidak dapat langsung digunakan melainkan harus diproses terlebih dahulu. Pengomposan dengan penambahan bahan alkalin dapat menjadi alternatif dalam menurunkan konsentrasi Fe dan Mn.

\section{UCAPAN TERIMAKASIH}

Ucapan terima kasih penulis sampaikan kepada pimpinan dan staf PT. Berau Coal, Kabupaten Berau, Kalimantan Timur yang telah memberikan kesempatan dan berbagai fasilitas yang diperlukan selama pelaksanaan penelitian ini.

\section{DAFTAR PUSTAKA}

Bohn H.L, Brian L.M, and Goerge A.O. 1979. Soil Chemistry. John Wiley and Sons. New York-Chichester-BrisbaneToronto. 
Munawar, A. 2007. Pemanfaatan sumberdaya biologis lokal untuk pengendalian pasif air asam tambang: lahan basah buatan. JITL 7(1) hal: 31-42.

Nyquist, J and Greger, M. 2009. A field study of constructed wetlands for preventing and treating acid mine drainage. Eco. Eng. Jour. 35. p 630-642.

Chen, W., Z. Chen, Q. He, X. Wang, C. Wang, D. Chen, and Z. Lai. 2007. Root growth of wetland plants with different root types. Acta Ecologica Sinica 7(2): 450 $-457$.

Davis, L. 1995. A Handbook of Constructed Wetlands, Volume 1, General Consideration. US Environmental Protection Agency (EPA). Washington DC.

Rout, G.R. and Sahoo, S. 2015. Role of iron in plant growth and metabolism. Reviews in Agricultural Science 3: 1 24.

Skousen, J.G., and P.F. Ziemkiewicz. 1996. Acid mine drainage control and treatment. $2^{\text {nd }}$ Edition. National Research Center for Coal and Energy, West Virginia University, Morgantown, WV.

Skousen J, A. Rose, G. Geidel, J. Foreman, R. Evans, and W. Hellier. 1998. Handbook of Technologies for Avoidance and Remediation of AMD. The National Mine Land Reclamation Centre. West Virginia.

Yang J, and Ye Z. 2009. Metal accumulation and tolerance in wetland plants. Frontiers of Biology in China Journal. 4(3): 282-288. 